\title{
In Situ Measurement of Discomfort Curves for Seated Subjects in a Car on the Four-Post Rig
}

\author{
T. Ibicek and A. N. Thite \\ Mechanical Engineering and Mathematical Sciences, Faculty of Technology, Design and Environment, \\ Oxford Brookes University, Wheatley, Oxford OX33 1HX, UK
}

Correspondence should be addressed to A. N. Thite; athite@brookes.ac.uk

Received 8 January 2014; Revised 12 June 2014; Accepted 3 July 2014; Published 4 August 2014

Academic Editor: Marc Thomas

Copyright (C) 2014 T. Ibicek and A. N. Thite. This is an open access article distributed under the Creative Commons Attribution License, which permits unrestricted use, distribution, and reproduction in any medium, provided the original work is properly cited.

\begin{abstract}
The aim of this study is to measure and quantify perceived intensity of discomfort due to vibration in a vehicle in situ considering complete vehicle dynamic behaviour. The shaker table based discomfort curves or the road test results may not accurately and universally indicate the true level of human discomfort in a vehicle. A new experimental method, using a seated human in a car on the four-post rig simulator, is proposed to quantify discomfort. The intensity of perception to vibration decreased with decreasing input and increasing frequency; the rate of change is different from the published literature; the difference is large for angular modes of inputs. Vehicle dynamic response is used to inform and analyse the results. The repeatability of the method and the fact that they are in situ measurements may eventually help reduce reliance on the road tests. Furthermore, discomfort curves obtained, subsequently, can be used in predictive models.
\end{abstract}

\section{Introduction}

One of the measures of vehicle competitiveness is the vehicle ride comfort. The manufacturers allocate significant resources in order to improve the performance by making appropriate vehicle design refinements. The requirements which are contradictory often result in a compromised solution. The variables involved in the multidisciplinary design are many. One such variable is the human perception of vehicle vibration, which significantly depends on the vibratory excitation spectrum and the duration of exposure. The vibratory inputs, often correlated and model specific, are dependent on the vehicle dynamics and the road inputs. Furthermore, the feeling of discomfort may depend on the system surrounding the occupant-seat combination. All these complexities make the design for good ride comfort performance, in general, very difficult to achieve. Often prototype based experimental optimization approaches are used by the industry, which are inefficient and costly and may not be repeatable. Ideally, it is desirable to have predictive models which, however, require the knowledge of the relation between the vehicular vibration stimulus and the intensity of perceived discomfort. Considerable literature is available on quantification of vibration perception based on idealized excitation. It is not known how well these results relate to in situ perception. The current study aims to measure and quantify perceived intensity of discomfort due to vibration in a vehicle, considering complete dynamic behaviour of the vehicle and, eventually, generating in situ measured discomfort curves which can be compared with previously published results.

In the industry and in some research studies, the vehicles are driven on different types of roads and the perception of drivers is collated to determine discomfort, for example, as in Kyung et al. [1]. The road tests in a vehicle, however, may have significant uncertainties as (a) the inputs may not be repeatable and hence statistics are not consistent and (b) the uncertainties in human perception may be difficult to quantify. Another alternative, the lab based discomfort indices developed using the shaker table tests [2-4] cannot be used to accurately quantify vehicle ride comfort as discomfort curves measured based on shaker table simulators lack the exact simulation of vehicle dynamics; the shaker table based data may not account for the influence of the surroundings 


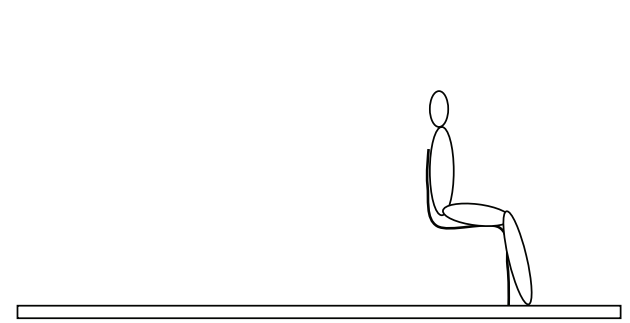

(a)

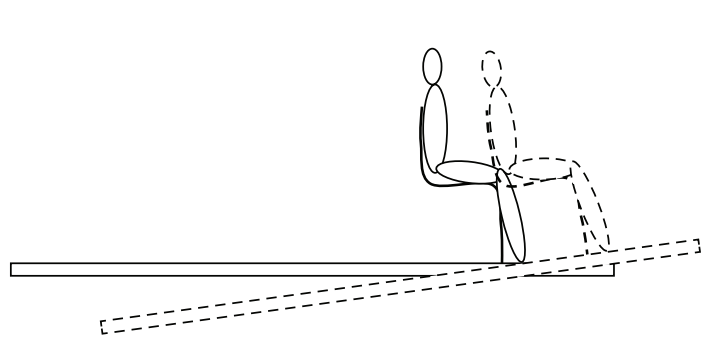

(c)

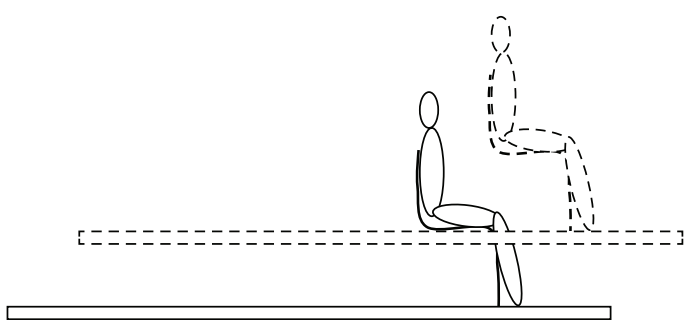

(b)

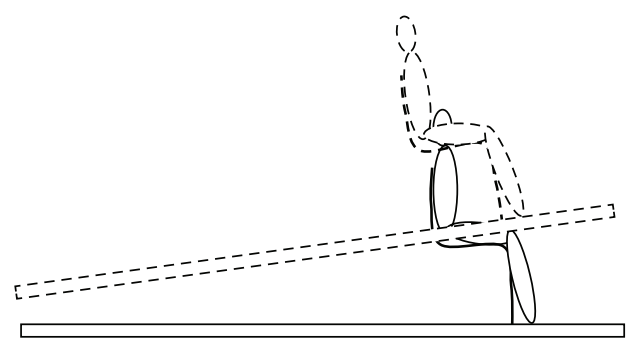

(d)

FIGURE 1: Comparison of commonly used simulator tables in discomfort studies and the vehicle-seat motion: (a) platform and the seated subject, (b) fore-aft motion in combination with vertical motion, (c) fore-aft motion in combination with pitching motion, and (d) vertical motion in combination with pitching motion as in vehicles.

on the discomfort. For example, the presence of steering wheel and foot pedals may have some influence on the perceived discomfort. Furthermore, some input aspects are not accounted for in current shaker table tests such as the correlated inputs that are experienced by road cars. Critically, the road inputs to any vehicle can result in a complex form of vibration consisting of vertical motion (heave or bounce) superimposed by rotational motion (pitch, roll, and yaw). For example, the change in angular orientation of the seat and occupant observed in vehicles is not simulated in the shaker table measurements (Figure 1).

The research on the influence of seat backrest on the effects of vibration [5-8] has grown rapidly and has been widely recognised as an important influence. The effect of seat backrest angle on the perceived discomfort was shown by Basri and Griffin [5]; in general, the angle other than upright position reduced perceived discomfort for any input level. Additionally, the research also discusses principal locations in human body where the difference in perception was felt. Another article [6] published at about the same time discusses the influence of backrest angle on the frequency weighting curves. There is a significant difference in findings from existing standards, in both levels and frequency distribution. These recent publications can have major influence on the methods used to quantify and predict vehicle ride comfort. There are other studies which addressed the effect of backrest angle on fatigue and cognitive performance. The seat backrest angle was shown [7] to influence spinal shrinkage based on the duration of exposure to vibration which can have an influence on the driver fatigue. The same factor was, however, shown [8] not to influence cognitive performance of the driver.

There are other approaches that have been used to quantify discomfort in a relative sense; one approach, where the effect of vehicle dynamics is isolated, is by defining discomfort based on the vibration levels on the seat $[2,3]$. There are standards written on the test procedures and analysis of the results [9] to assess seat effectiveness. The applicability of these measures to accurately predict vehicle discomfort is unknown [2]. Vibration transmissibility [2, 10, 11] and apparent mass $[2,12]$ have been used to analyze the influence of occupant-seat dynamics. The transmissibilities of seat-tohead, road-to-vehicle floor, road-to-driver seat, and seat-tohuman can also be used to define the discomfort metric. Overall, the results based on transmissibility and seat vibration measurements provide a great deal of information, but they are only approximate measures. There have been limited experiments conducted on vehicles using repeatable inputs; in some studies [13-16], vehicle dynamics and complexity of seat-driver response were explored to a limited extent.

The present study focuses on the experimental approach to develop discomfort indices by (a) using the inputs that are repeatable and (b) considering the complex behaviour of the vehicle to a given input. The use of a four-post rig will allow consideration of complete vehicle dynamics. The experiments can be conducted to simulate vehicle travelling in a straight line, taking a turn, and changing a lane; the controlled actuation of the four posts allows replication of the driving situations. In effect, a participant will feel a "real" driving condition as experienced on the road when sitting in the car. To perform these types of experiments on shaker tables, significant background information on the vehicle being tested, vehicle dynamics, and the road condition and associated occupant information is required. In four-post rig tests, additional information about combination of vehicle dynamics and human body dynamics like vibration transfer from the road to the vehicle floor, driver seat, and driver body because of heave, pitch, and roll motion can also be 
quantified. Briefly, it allows creation of discomfort metric for different test setups at varying frequencies, input levels, and specified exposure time.

The experiments on the four-post rig were conducted on twenty-four seated participants sitting on the driver's seat in a car on the four-post rig with an exposure of 17 seconds, who were asked to provide a perception rating. A discomfort scale and vibration input levels were determined based on the safely achievable vibration levels on the seat, using a pilot study [17]. To simulate driving conditions, to an extent, the participants were asked to hold the steering wheel and use the accelerator pedal. The database generated was used as a reference to develop discomfort metric for an integrated human-seat-car behaviour. In what follows, the test procedure is briefly discussed providing details of the setup, the discomfort scale, vibration input, vehicle dynamic response, and procedure. The vibration responses and corresponding intensities of perception are critically analysed. The influence of physical characteristics of participants, mainly the effect of mass, is discussed. The effect of vehicle parameter nonlinearities on the experiment design is shown. The deviation of discomfort curves for pitch and roll input from the existing published information is discussed.

\section{Experiment Design and Procedure}

Essential requirements of in situ vehicle vibration based discomfort assessment experiments are (a) a mechanism to vibrate the vehicle in a controlled manner, (b) instrumentation to measure dynamic response, and (c) a subjective rating scheme to relate physical stimulus and the intensity of vibration perception. As road vehicles are complex dynamic systems, generation of controlled physical stimulus requires greater understanding of the vehicle under experiment. In this study vehicle dynamic features are identified using preliminary experiments.

In the following sections, the aspects of vehicle dynamics that are important for the experiment are discussed in terms of modes of vibration. The information of dynamic behaviour is then used to achieve controlled inputs to the seated driver. The instrumentation, actuation mechanism, and test setup are briefly described and later a subjective rating used in the experiments is introduced.

2.1. Controlled Vehicle Input. Four-post rig which is an electrohydraulic actuator setup along with the vehicle acts as a simulator allowing replication of the effects of road surfaces on vehicles to primarily test suspension systems $[18,19]$ for vehicle handling performance; in this study, the scope of the test is extended so that the rig acts as a simulator to conduct experiments to investigate occupant discomfort. As the name suggests, four-post rig comprises of four actuators, one supporting each wheel. On top of each actuator there is a wheel pad on which wheels rest. The position of each actuator can be controlled independently to impart required displacement, velocity, and acceleration.

The patterns of motion of vehicle considered in this study are (a) heave (bounce): vehicle vertical motion in $z$-direction,

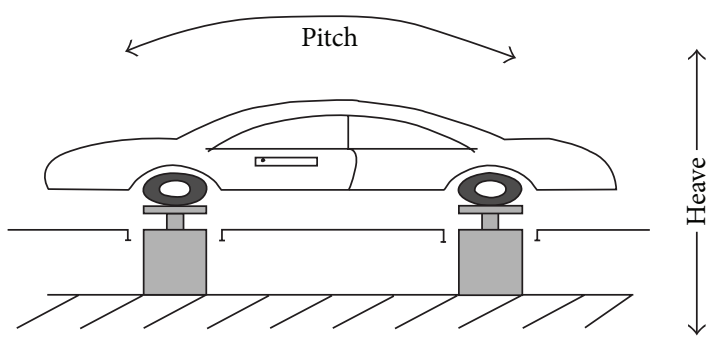

(a)

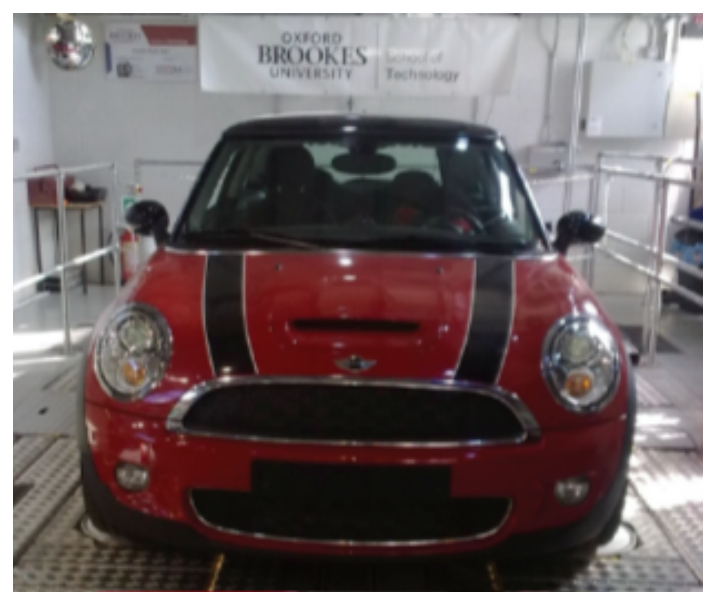

(b)

FIGURE 2: The arrangement of a vehicle on the four-post rig electrohydraulic shakers: (a) the schematic of the experimental arrangement and (b) front view of the vehicle on the four-post rig.

(b) pitch: rotation of the vehicle about its lateral axis, that is, $x$-direction, and (c) roll: rotation of the vehicle about its longitudinal axis, that is, $y$-direction. The pitch motion is the primary source of longitudinal vibrations at locations away from the centre of gravity. In the heave motion, whole vehicle rises and falls evenly, with no rotation about any axis. Apart from pitch and heave motion, vehicle roll can become important input when a vehicle is taking a turn.

In general, due to vehicle dynamics it is highly unlikely to be able to generate pure heave or pitch or roll motion which can be a limitation; it is not feasible to replicate the results of the shaker table tests. On the other hand, as the vehicle dynamic behaviour is never purely a motion of heave or pitch or roll, the setup can be advantageous in replicating "real" motion. In practice all three modes of motion occur in combination but one of them is dominant at any point of time.

As a practical solution, as coupled motion of vehicle cannot be avoided, following patterns of inputs are used in this study. All four wheel pads move in phase for heave input, two front and two rear wheel pads move out of phase for pitch input, and two right and two left wheel pads move out of phase for roll input. In the experiments, a small car was positioned (Figure 2) on the rig to generate seat-occupant response and eventually conducted discomfort quantification exercise. The parameters of the car are number of doors: 5 , total mass: $1200 \mathrm{~kg}$, wheelbase: $2.47 \mathrm{~m}$, track width: $1.46 \mathrm{~m}$, 
vertical distance from front axle to the centre of gravity: $0.871 \mathrm{~m}$, and horizontal distance from front axle to the centre of centre of gravity: $1.596 \mathrm{~m}$.

2.1.1. Physical Stimulus. The current experimental study requires calculation of road inputs that are needed to generate a particular level of physical stimulus at the seat-occupant interface. The road input is filtered by the dynamics of car and seat-occupant combination. Although random inputs could be used in the experiments to replicate the road profile, to understand the effect of input frequencies and levels, sinusoidal inputs are preferred. This allows (a) development of input frequency and level based discomfort metric and (b) assessment of the effect of combined resonant behaviour of the vehicle and human subject dynamic system.

The vehicle-occupant system natural frequencies play an important role in determining frequency response at seat and occupant interface. Furthermore, the presence of nonlinearities in vehicle dynamic parameters may influence the experiment design as well as the seat-occupant behaviour. Then, there is variability due to participants. The participants of the experiments due to differing physical characteristics, mainly the effect of mass, can influence the vibration response; the experimental inputs required may change as well; importantly, the vibration input experienced by the passenger may vary. All these aspects are discussed with appropriate governing equations so as to analyse their influence.

2.1.2. Vehicle Suspension Dynamics and Road Input: The Effect of Resonances. An input to occupant through car seat is made of complex contributions from vehicle system resonances. The input can be written in terms of transfer function relating the vibration energy transfer. In the frequency domain, the relation is given by

$$
Y(\omega)=\frac{X(\omega)}{H(\omega)},
$$

where $X$ is the output displacement, $Y$ is the input displacement, $\omega$ is the excitation frequency, and $H$ is the related frequency response function. The resonances, dominantly, contributing to the frequency response function are (a) vehicle bounce mode, (b) vehicle pitch mode, (c) vehicle roll mode, (d) wheel hop frequencies, and (e) seat resonances. The frequency response function can be expressed in terms of these resonances. For a linear system, using system natural frequencies, the frequency response can be written as

$$
H(\omega)=k_{t} \sum_{n=1}^{k} \frac{\phi_{n}\left(z_{1}\right) \phi_{n}\left(z_{2}\right)}{\left(\omega_{n}^{2}-\omega^{2}\right)+j 2 \Delta_{n} \omega},
$$

where $\Delta_{n}=\zeta_{n} \omega_{n}$ is the damping bandwidth, $\zeta_{n}$ is the modal damping ratio, $\omega_{n}$ is the $n$th natural frequency, $\phi_{n}\left(z_{1}\right)$ is the mass normalized $n$th mode shape function at the response measurement location $z_{1}, \phi_{n}\left(z_{2}\right)$ is the mass normalized $n$th mode shape function at the forcing location $z_{2}$, and $k_{t}$ is the effective tyre stiffness. The dynamic parameters controlling resonances are difficult to determine accurately; that is, although lumped parameter models are available to predict the dynamic behaviour, the parameters themselves are not. To overcome the difficulty, frequency response functions can be experimentally determined; the peaks of the frequency response function are dominant resonances. These resonances provide valuable information later in the postprocessing phase as they help critically analyse the results of perceived discomfort.

2.1.3. Experimentally Obtained Input-Output Relation: The Effect of Nonlinearities. Experimentally obtained frequency response functions, ideally, help identify input parameters for controlling seat-occupant response. The process may not be straightforward if nonlinearities are present. A few parameters of vehicle-occupant system are nonlinear with respect to displacement and velocity. Therefore, the calculation of required road input for any target level of acceleration at seatoccupant interface based on (1) can be erroneous. The level of error depends on the degree of nonlinearity. The nonlinearity may vary as a function of frequency of excitation mainly due to the amplifying effect of particular parameters affecting regions around resonance frequencies. In general, (1) needs updating for a nonlinear behaviour as

$$
Y(\omega, \dot{x}, x)=\frac{X(\omega)}{H(\omega, \dot{x}, x)} .
$$

Theoretical calculation or for that matter experimental estimation of nonlinear frequency response function is difficult. In the current study, in order to overcome the difficulty, the effect of nonlinearity was assessed experimentally only at the frequencies of interest; the magnitude of frequency response function, $H(\omega, \dot{x}, x)$, was measured for several input amplitudes. The relation between frequency response amplitude and the road input was obtained graphically; constant slope would indicate linearity. Using these experimentally obtained relations, the inputs required at the car tyres to achieve particular seat-occupant motion can be estimated giving due consideration to the nonlinearities present.

2.1.4. Inherent Variability: Occupant Mass Influence. The dynamics of seat-occupant and to a lesser extent the vehicle itself is influenced by the occupant (participants in the experiment) details. Invariably, the mass, stiffness, and geometrical shape of participants taking part in the experiments differ. For a particular value of damping, the variation in mass and stiffness can have a complex effect on the natural frequencies. This in turn can influence amplitudes at resonances. Out of the two, relatively, mass variation can be easily measured and its effect on the natural frequencies is estimated. Although stiffness variation is not easy to measure, it inversely influences the natural frequencies. In practice, the effect of varying mass and stiffness can be replaced by an equivalent variation in the mass. Further simplifications can be made by assuming a rigid car floor, which implies a linear system; the floor on which seat is mounted is relatively unaffected by the change in mass of participants; hence, seat-occupant response can be analysed separately considering only the vertical motion. The variations in natural frequency, damping ratio, and eventually the response peak amplitude from base value for a small 
change in mass can be estimated using the expressions given below:

$$
\begin{aligned}
\delta \omega_{d} & =-\frac{\omega_{n}\left(1-2 \zeta^{2}\right)}{2 m \sqrt{1-\zeta^{2}}} \delta m, \\
\delta Q & =\frac{\omega_{n}}{2 c} \delta m,
\end{aligned}
$$

where $\omega_{n}$ and $\omega_{d}$ are natural frequency and damped natural frequency, respectively, $m$ is the mass, $c$ is the damping coefficient, and $Q$ is the crest factor. The crest factor is a measure of the peak response amplitude attained by a single degree freedom system. For increased mass, the seat-occupant peak response amplitude should increase (5) and the damped natural frequency should decrease (4). The variations in crest factor and the damped natural frequency are expected to influence human response due to vibration. The degree of influence may vary.

2.2. Instrumentation. The acceleration responses at various positions were acquired using custom built data acquisition system controlled by Dynosoft MX multi-axis test control and acquisition software, at the rate of 200 samples per second. The system allows the use of excitation frequencies of up to $50 \mathrm{~Hz}$; however, full range will not be used in this investigation. Vibration responses were measured using SD Silicon Design 2210 accelerometers which have sensitivitydifferential of $400 \mathrm{mV} / \mathrm{g}$ and a range of $\pm 10 \mathrm{~g}$. In the experiment, three accelerometers were mounted on the floor of the front passenger seat and three were mounted on the seat surface to measure multidirectional motion of the floor and seat, respectively.

\subsection{Intensity of Perception: Discomfort Scale. There are sev-} eral discomfort scales and associated vibration levels available from the published data, mainly using shaker table tests, relating the intensity of perception to physical stimulus [4, 20-22]. These scales cannot be adapted for this study straightforwardly for the reason that the vibration levels achievable at the seat-occupant are restricted by the dynamics of the car. The amplitudes and frequencies for pitch and roll are restricted by the stability of the car on the four-post rig. The angular motion required to achieve seat vibrations at these frequencies requires inputs which are so large that the car would slide sideways and forward, respectively, in roll and pitch, eventually in danger of coming off the wheel pads. This occurs at lower frequencies.

The seat and occupant interface r.m.s acceleration levels achievable without stability concerns are in pitch and roll input $0.63 \mathrm{~m} / \mathrm{s}^{2}$ at $2 \mathrm{~Hz}$; in heave input $1 \mathrm{~m} / \mathrm{s}^{2}$ could be achieved at $1 \mathrm{~Hz}$. The discomfort scale, therefore, will be defined based on these levels which unfortunately may not allow the comparison of outcomes of the current study with the published data, but the advantage is that the levels are more likely to be experienced by vehicle occupants than the larger values. The chosen discomfort scale is given in Table 1. The vibration perceived is rated on a scale from 1 to 5 with the
TABLE 1: Discomfort definition and the scale used in the experiment.

\begin{tabular}{lc}
\hline Perception & Rating \\
\hline Not discomfortable & 1 \\
Noticeable but not discomfortable & 2 \\
Slightly discomfortable & 3 \\
Discomfortable & 4 \\
Highly discomfortable & 5 \\
\hline
\end{tabular}

feeling of being not discomfortable to highly discomfortable, respectively.

\section{Measurements}

3.1. Participants. The experimental study was conducted on twenty-four healthy participants ( 6 females, 18 males). The details of the procedure and the discomfort scale were discussed with participants before the start of the experiments. The physical parameters of participants were noted as these details can have a significant influence on the outcome of the study. For example, in the study by Jones and Saunders [4], a reduction in the vibration response was observed for the increased body length. The age, height, and weight of the participants (listed in Table 3) were in the range 19-36 years, $1.57-1.99 \mathrm{~m}$, and $50-100 \mathrm{~kg}$, respectively. The experiment was approved by the Ethics Committee of Oxford Brookes University and Health and Safety of School of Technology.

3.2. Procedure. At the start of the experiments, the subjects sat inside the car in comfortable driving sitting posture, looking straight ahead, with their hands on the steering wheel, wearing a seat belt, and with backrest contact. Based on the knowledge of vehicle dynamics, the seated subjects were exposed to the target vertical seat root mean square accelerations of $0.1,0.25,0.4,0.63$, and $1 \mathrm{~m} / \mathrm{s}^{2}$ in heave motion from $1 \mathrm{~Hz}$ up to $15 \mathrm{~Hz}$ frequency range; $0.1,0.16,0.25,0.4$, and $0.63 \mathrm{~m} / \mathrm{s}^{2}$ (seat vertical r.m.s acceleration for given angular input on the wheels) in pitch and roll motion from $2 \mathrm{~Hz}$ up to $15 \mathrm{~Hz}$. For roll and pitch motion at $1.75 \mathrm{~Hz}$ only three magnitudes of $0.1,0.16$, and $0.25 \mathrm{~m} / \mathrm{s}^{2}$ were used. The exposure duration (much less than 10 minutes) and the weighted acceleration (less than $1 \mathrm{~m} / \mathrm{s}^{2}$ ) [9] were determined according to the guide limits of ISO 2631-Health Caution Zones.

In the experimental protocol, after going through vibration inputs at a frequency, the subjects were asked to assign a number representing the discomfort scale. In the excitations for particular car motion, the rig started from a standstill position; therefore transients and associated frequency contamination may be a concern. To overcome anticipated difficulties, the frequency and amplitude were gradually increased from zero to the required values so that no transients were experienced. The excitations were such that by $2 \mathrm{sec}$ the input reached required values and it stayed the same until $13 \mathrm{sec}$ and after that gradually reduced to zero amplitude. In the postprocessing, the amplitude within the constant input time period was used to develop discomfort metric. 


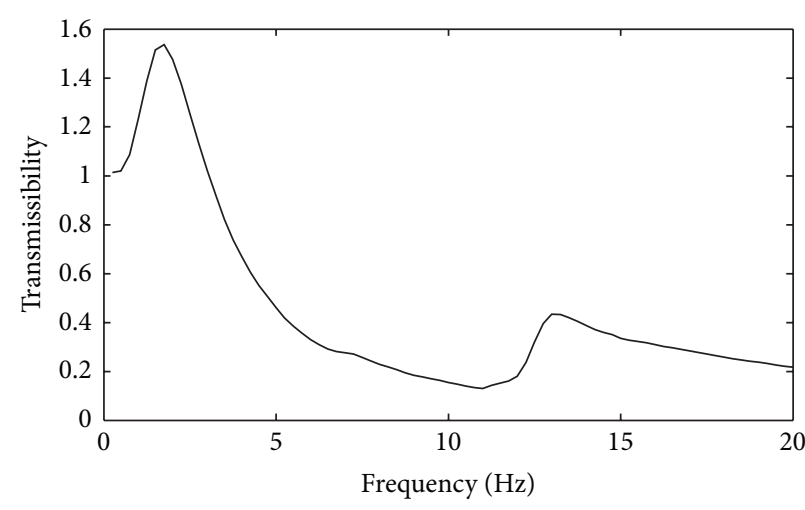

(a)

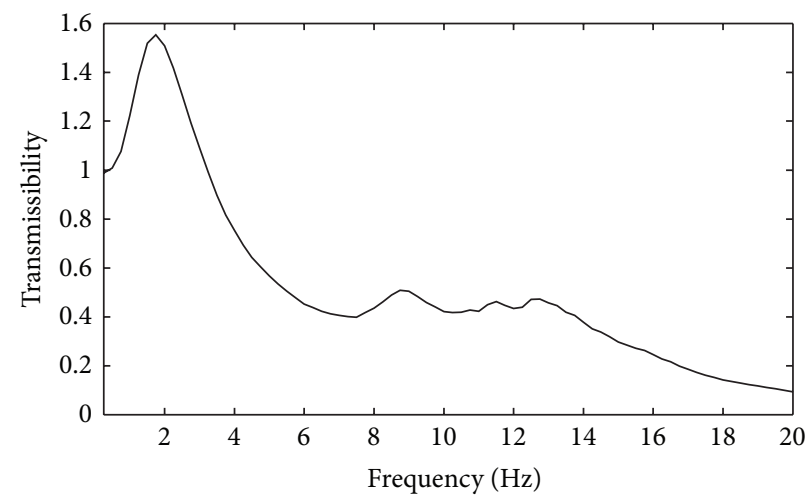

(b)

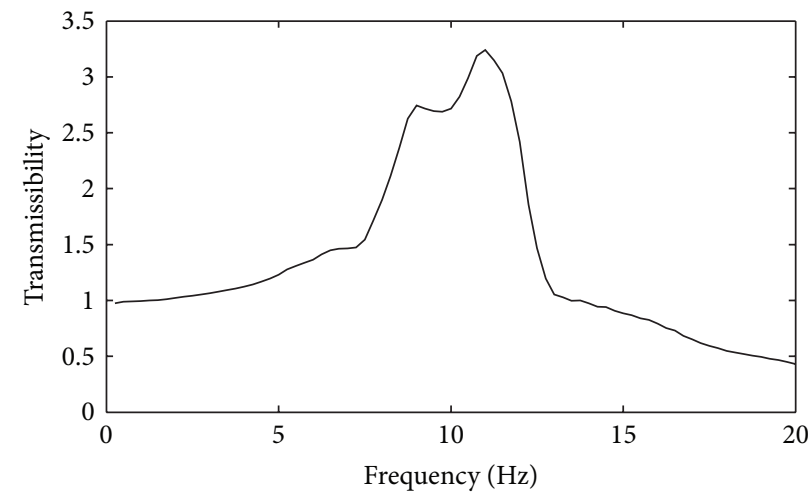

(c)

FIGURE 3: Measured vibration transmissibilities in heave input mode: (a) from wheel pad to the vehicle floor, (b) from wheel pad to the seat, and (c) from vehicle floor to the seat.

TABLE 2: Dominant resonance frequencies and associated amplification factors at seat capturing vehicle-seat-occupant dynamic behaviour.

\begin{tabular}{lccc}
\hline Resonance frequency & Mode & Input-output & Amplification factor \\
\hline $1.75 \mathrm{~Hz}$ & Vehicle bounce & Road to seat & 1.55 \\
$9 \mathrm{~Hz}$ & Seat bounce & Floor to seat & 2.7 \\
$11 \mathrm{~Hz}$ & Seat + backrest motion & Floor to seat & 3.25 \\
$12 \mathrm{~Hz}$ & Seat pitch & Floor to seat & $1.7 \mathrm{~m} / \mathrm{rad}$ \\
$13 \mathrm{~Hz}$ & Seat Roll & Floor to seat & $1.15 \mathrm{~m} / \mathrm{rad}$ \\
$13 \mathrm{~Hz}$ & Wheel hub & Road to seat & 0.5 \\
\hline
\end{tabular}

\section{Results and Discussion}

4.1. Resonance Behaviour of Vehicle and Seat. The vibration response transmissibilities between road and vehicle floor, road and seat, and vehicle floor and seat are shown in Figure 3. In Figure 3(a), floor frequency response (i.e., eventual input for the seat vibration studies) with respect to the wheel pad inputs is given; wheel pad motion is the source of vibration that simulates the road and tyre contact. The vehicle shows clearly defined resonant behaviour. First dominant peak occurs at $1.75 \mathrm{~Hz}$ where the transmissibility is 1.5 which corresponds to the car bounce or heave mode of vibration; second peak, which is due to the wheel motion dominant mode (generally called wheel hop or hub mode) of the car, occurs at $13.25 \mathrm{~Hz}$ where the transmissibility is 0.4 . There are also small response contributions around $8 \mathrm{~Hz}$.
Figure 3(b) shows vibration response transmissibility to the seat. Here again, first peak shows the contribution of car bounce resonance at $1.75 \mathrm{~Hz}$. The response has three significant peaks between 8 and $13 \mathrm{~Hz}$ which are due to dynamics of the seat. This is further confirmed in Figure 3(c), where vibration response transmissibility to seat from the floor is given. The seat cushion and seat backrest resonances appear to contribute to the response at these frequencies. Based on all the measurements on the car for heave, pitch, and pitch motion inputs, dominant resonances and corresponding amplification factors are listed in Table 2 . The seat bounce, pitch, and roll have significant amplification factors at frequencies $11 \mathrm{~Hz}, 12 \mathrm{~Hz}$, and $13 \mathrm{~Hz}$, respectively.

4.2. Nonlinear Behaviour of Vehicle Suspension and Seat Combination. Figure 4 shows the relation between road input and 


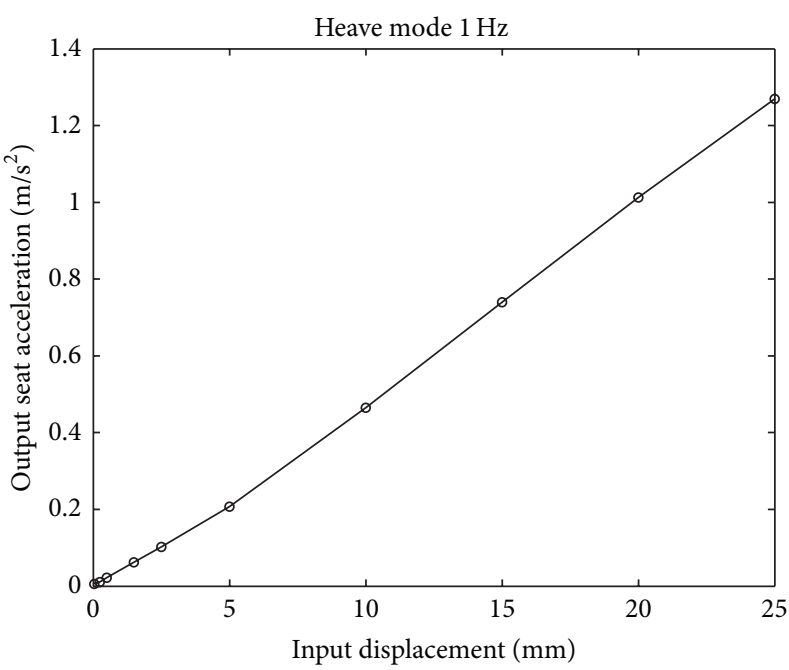

(a)

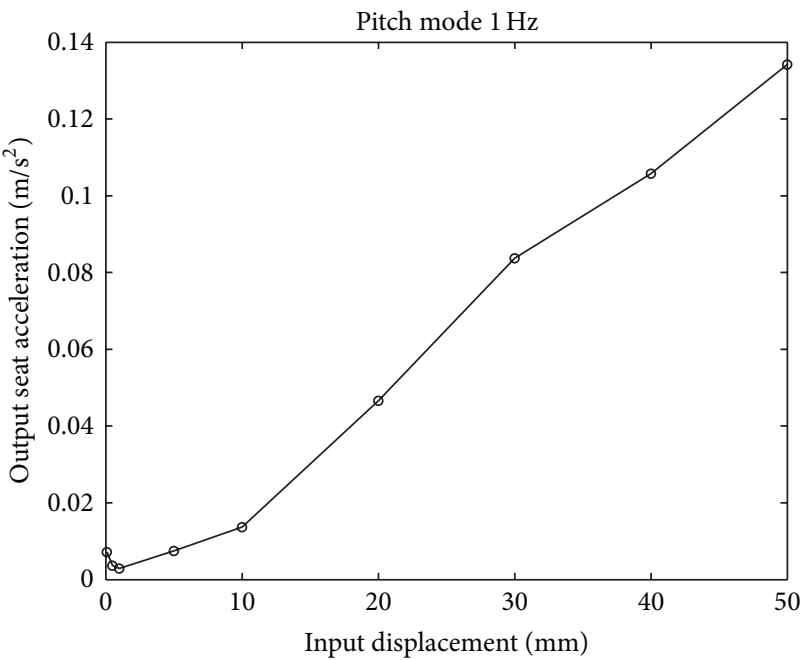

(c)

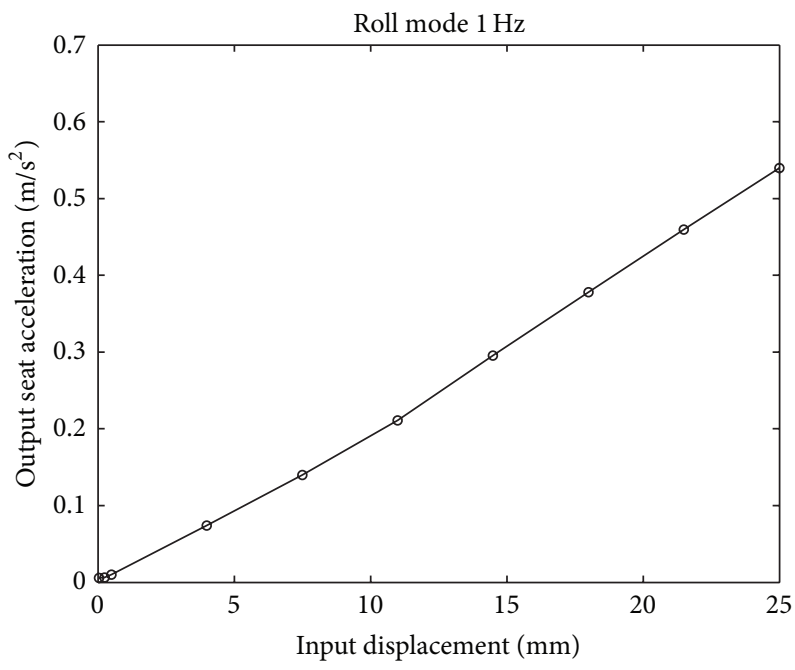

(e)

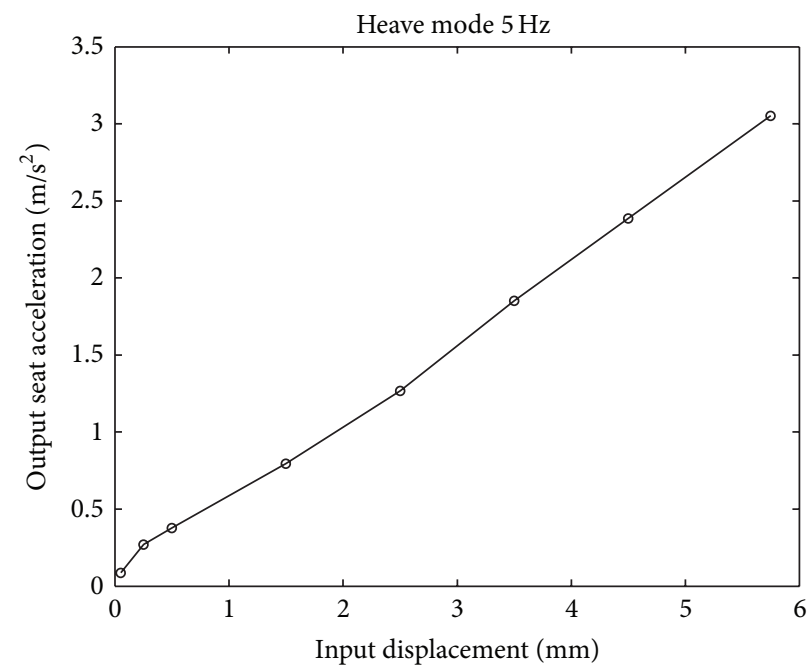

(b)

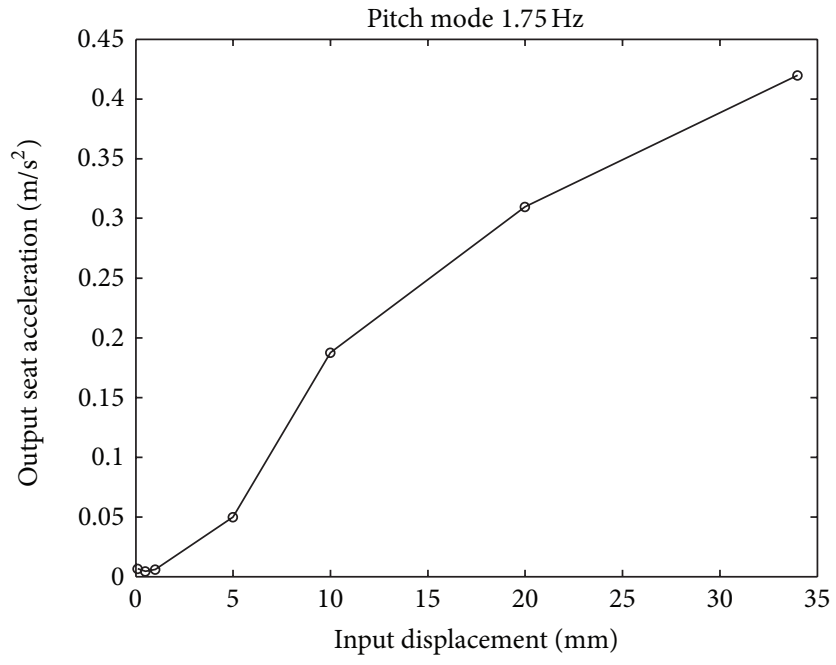

(d)

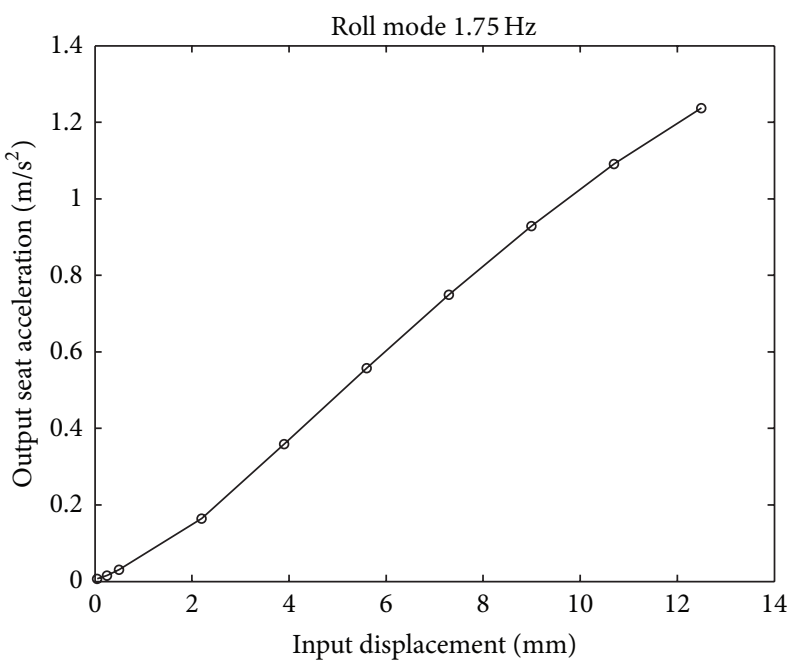

(f)

FIGURE 4: Road input and seat output acceleration relation for the test vehicle in different input modes. Heave input mode: (a) $1 \mathrm{~Hz}$ and (b) $5 \mathrm{~Hz}$, pitch input mode: (c) $1 \mathrm{~Hz}$ and (d) $1.75 \mathrm{~Hz}$, and roll input mode: (e) $1 \mathrm{~Hz}$ and (f) $1.75 \mathrm{~Hz}$. 


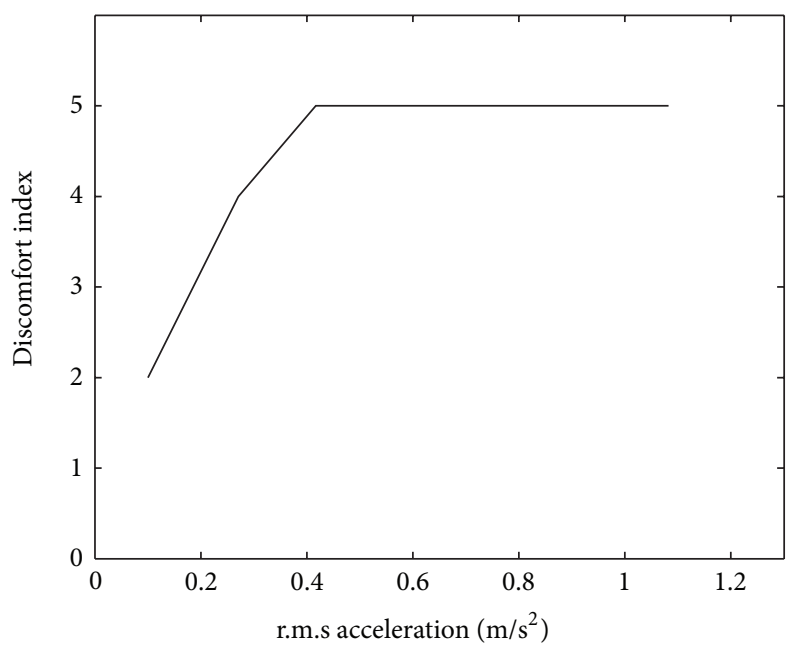

(a)

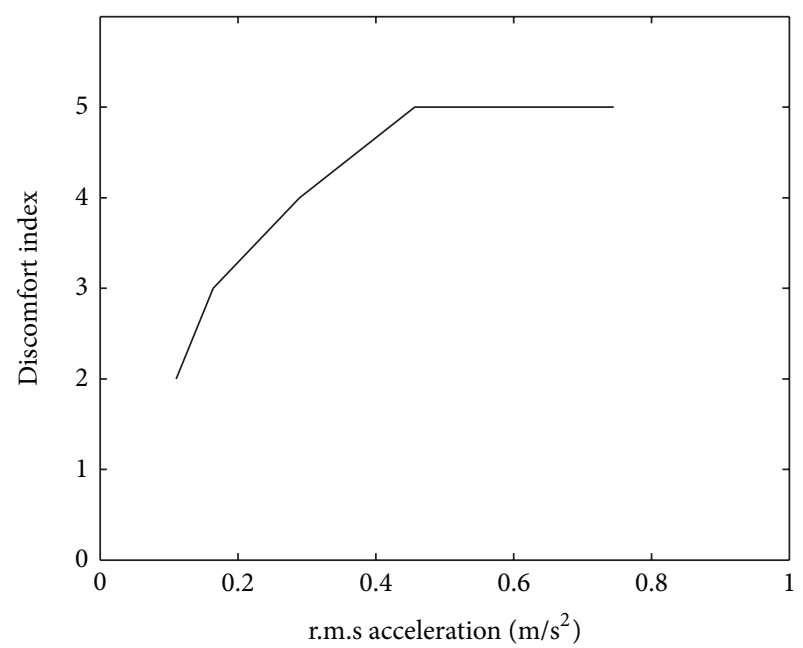

(b)

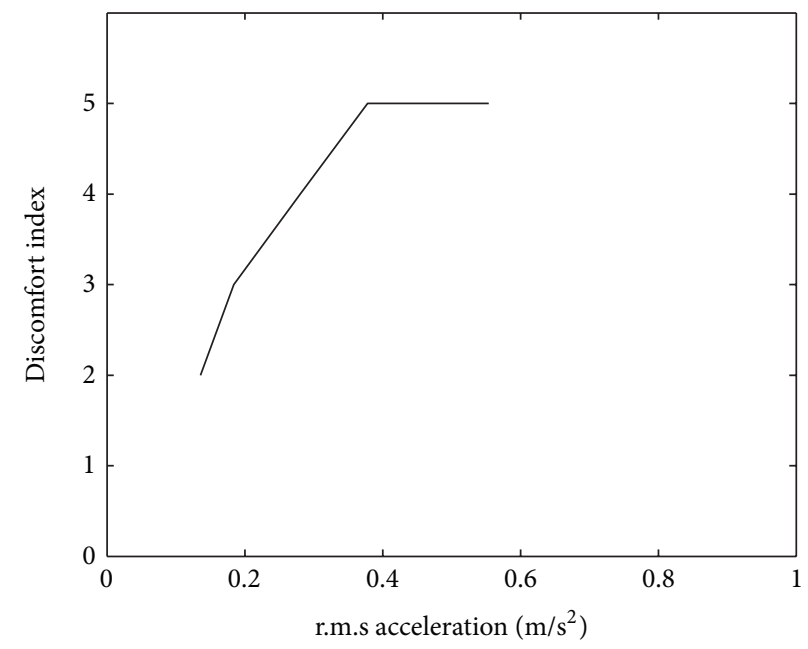

(c)

FIGURE 5: Discomfort index as a function of seat-occupant r.m.s acceleration level at $5 \mathrm{~Hz}$ for a participant. (a) Heave mode of input, (b) pitch mode of input, and (c) roll mode of input.

acceleration response on the seat for excitations in heave, pitch, and roll mode, respectively. The results are shown at two frequencies for varying road input amplitude. For heave input (Figures 4(a) and 4(b)), the relationship is weakly nonlinear at both $1 \mathrm{~Hz}$ and $5 \mathrm{~Hz}$. The behaviour is almost linear for larger excitation amplitudes. Overall, for heave input, the relation can be approximated as being linear. For pitch input (Figures $4(\mathrm{c})$ and $4(\mathrm{~d})$ ), the variation is very complex; the relation is nonlinear showing both softening type and hardening type of stiffness effect. For $1.75 \mathrm{~Hz}$ excitation, at lower amplitudes vehicle-seat dynamics shows softening behaviour. The behaviour turns hardening at larger input amplitudes for $5 \mathrm{~Hz}$ excitation. The bimodal behaviour could be due to the presence of both types of nonlinearities: seat foam is softening type, whereas the vehicle suspension system is hardening type. For roll mode road input (Figures 4(e) and 4(f)), the input-output relation is weakly nonlinear. The degree of nonlinearity as compared to heave mode is slightly larger. In summary, the degree of nonlinearity varies vastly depending on the mode of excitation. In effect, the calculation of inputs to generate a level of vibration at the seat-occupant interface is not straightforward.

4.3. Subjective Discomfort Assessment in Heave, Pitch, and Roll Mode Inputs. The measured data of twenty-four people was analysed relating acceleration level to the intensity of perception. Accordingly, discomfort indices were developed for heave, pitch, and roll modes at each frequency of excitation. The output accelerations and perception of vibration were analyzed, initially, separately for each participant; later, the results of all the participants were combined in order to explore the experimental variations.

Figure 5 shows discomfort indices of a participant for heave, pitch, and roll input modes, respectively, at $5 \mathrm{~Hz}$ excitation frequency. A fundamental feature of these plots is that they conform to a widely held view of (a) increased stimuli 
TABLE 3: The physical parameters of the participants.

\begin{tabular}{lcc}
\hline Participant number & Weight $(\mathrm{kg})$ & Height $(\mathrm{m})$ \\
\hline P1 & 78 & 1.76 \\
P2 & 83 & 1.84 \\
P3 & 81 & 1.81 \\
P4 & 60 & 1.8 \\
P5 & 90 & 1.99 \\
P6 & 67 & 1.85 \\
P7 & 67 & 1.65 \\
P8 & 84 & 1.8 \\
P9 & 76 & 1.75 \\
P10 & 85 & 1.8 \\
P11 & 95 & 1.8 \\
P12 & 70 & 1.82 \\
P13 & 73 & 1.82 \\
P14 & 59 & 1.66 \\
P15 & 76 & 1.79 \\
P16 & 77 & 1.73 \\
P17 & 50 & 1.56 \\
P18 & 55 & 1.7 \\
P19 & 55 & 1.76 \\
P20 & 100 & 1.72 \\
P21 & 75 & 1.6 \\
P22 & 48 & 1.83 \\
P23 & 90 & 1.58 \\
P24 & 54 & 1.57 \\
\hline
\end{tabular}

resulting in increased discomfort and (b) discomfort rating varying as a nonlinear function of stimuli. The roll and heave inputs at $5 \mathrm{~Hz}$ result in higher discomfort than pitch mode. In general, by analysis of results for frequencies up to $5 \mathrm{~Hz}$, even at lower input amplitudes, roll input shows higher perceived discomfort which is followed by pitch mode of input and then heave mode of input. These results are unlike those which have been reported and published in standards, for example, [9], where pitch and roll inputs show clearly reducing perceived discomfort around $5 \mathrm{~Hz}$ excitation; at frequencies above about $3 \mathrm{~Hz}$, the heave input should have been dominant. The deviation from earlier studies could be due to the presence of combination of motion at the seat-occupant interface for angular modes of inputs and the influence of vehicle roll and pitch natural frequencies. As shown in Figure 1, net vertical motion always occurs for angular motion inputs. Hence, for roll and pitch mode inputs, when pitch and roll natural frequencies are closer to the excitation frequency, the angular inputs may continue to dominate intensity of vibration perception. This is a fundamental difference between shaker table results and the current study.

The measurements of all 24 participants were postprocessed to obtain the discomfort index variation as a function of seat-occupant acceleration levels. Figures 6-8 show variation of discomfort indices at $3 \mathrm{~Hz}, 4 \mathrm{~Hz}, 6 \mathrm{~Hz}, 8 \mathrm{~Hz}$, and $10 \mathrm{~Hz}$ in heave, pitch, and roll input, respectively. Heave input mode (Figure 6(a)) was rated less discomfortable at $3 \mathrm{~Hz}$ than pitch
(Figure 7(a)) and roll (Figure 8(a)) input mode. Historically (e.g., $[2,9]$ ) it is known that, at lower frequencies, below $3 \mathrm{~Hz}$, angular inputs are dominant in determining the level of discomfort; at this frequency both pitch and roll mode inputs were perceived equally discomfortable. The variability in discomfort index is dissimilar for various inputs. At higher input amplitudes, the variability is smaller for the angular inputs; the heave input shows large perception variation throughout. Furthermore, there is variability in acceleration levels (data spread on $x$-axis) because of the influence of the occupant mass on the dynamics (5). This variability is the largest for the pitch input which is followed by roll and heave inputs. The input variability may not be the sole cause of variability in the vibration perception, as the least variable heave input has largest discomfort rating variation.

Figures 6(b), 7(b), and 8(b) show discomfort rating results for heave, pitch, and roll mode inputs at $4 \mathrm{~Hz}$, respectively. As anticipated, the discomfort level increases with frequency and vibration magnitude. The heave mode input is less discomfortable than other modes of inputs; furthermore, in comparison, roll mode was found more discomfortable than the pitch mode. However, when compared with the $3 \mathrm{~Hz}$ excitation, heave mode of input is more discomfortable. The variation in the seat vertical response continues to be larger for pitch mode input; it is slightly smaller for roll mode input but larger than that found at $3 \mathrm{~Hz}$. At higher input amplitudes, the response levels for the heave input show some variations. However, variabilities in discomfort ratings are similar for both 3 and $4 \mathrm{~Hz}$ excitation frequencies.

Figures 6(c), 7(c), and 8(c) show discomfort rating results for heave, pitch, and roll inputs at $6 \mathrm{~Hz}$; heave and pitch inputs were rated the most discomfortable; in fact, of 3,4 , and $6 \mathrm{~Hz}$ excitations in heave mode, $6 \mathrm{~Hz}$ was perceived most discomfortable. Significantly, the roll mode input was rated less discomfortable as compared to 3 and $4 \mathrm{~Hz}$ excitation. Furthermore, this input shows significant response variation as compared to the lower frequencies, so does the heave mode input. The variability of perception has increased for heave and pitch modes of inputs, in particular.

Figures 6(d), 7(d), and 8(d) show results for heave, pitch, and roll inputs at $8 \mathrm{~Hz}$, respectively; heave motion was rated highly discomfortable and roll motion was rated the least discomfortable. The trend of reduced significance for angular input continues at higher frequencies. All three excitations show considerable input acceleration variation. The variability of perceived discomfort is largest for the heave input, whereas it is smallest for the roll input. In fact, for the roll mode input at very low amplitudes, the variation is negligible.

Figures 6(e), 7(e), and 8(e) show results for heave, pitch, and roll input at $10 \mathrm{~Hz}$, respectively; the discomfort level has gone down considerably for pitch and roll inputs but slightly for heave input. The variability in perceived discomfort in heave and pitch mode inputs is much larger than that for roll mode. There is considerable variation in the seat-occupant response for all types of excitations.

Overall, the results are considerably different from the published literature. The dominant frequency regions differ. The effect of combined or coupled motion at the seat is clearly influencing the intensity of perception. The variability 


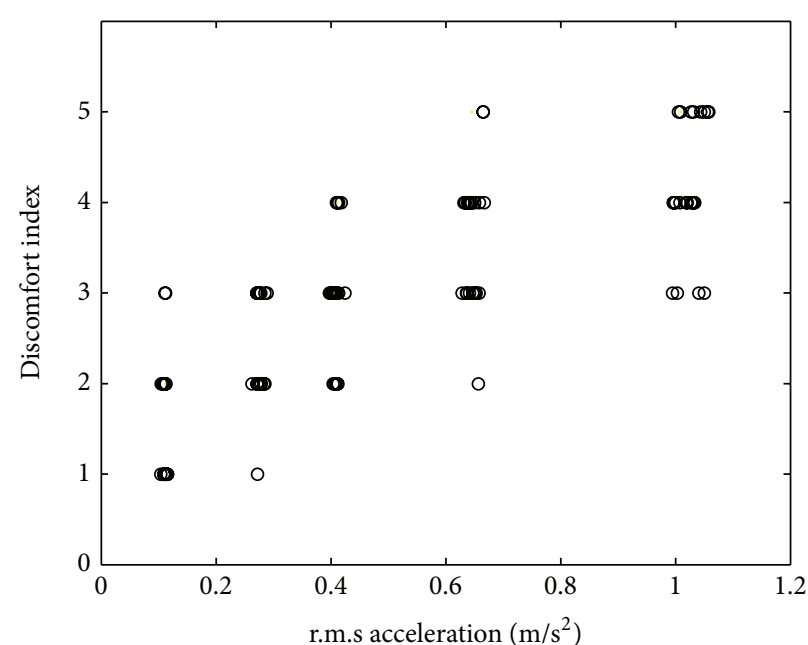

(a)

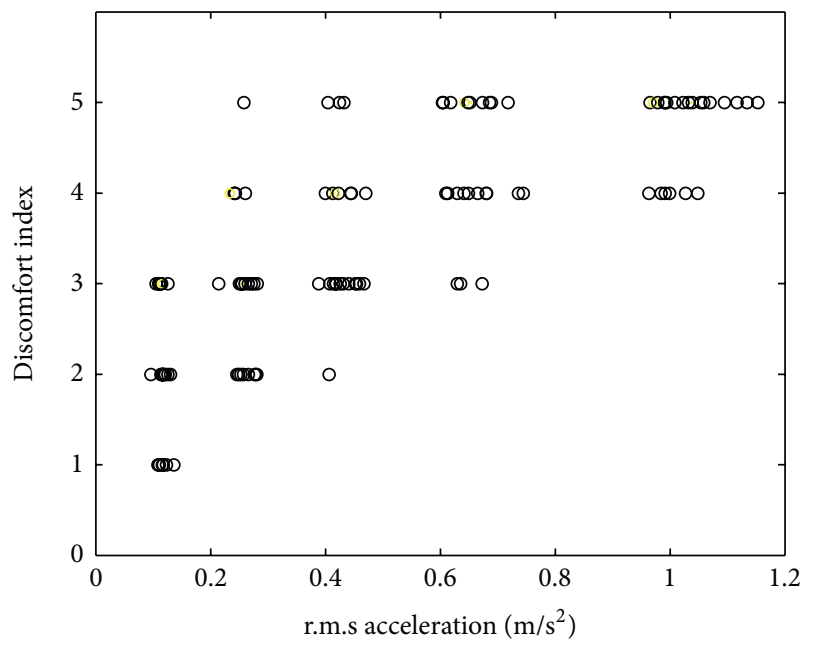

(c)

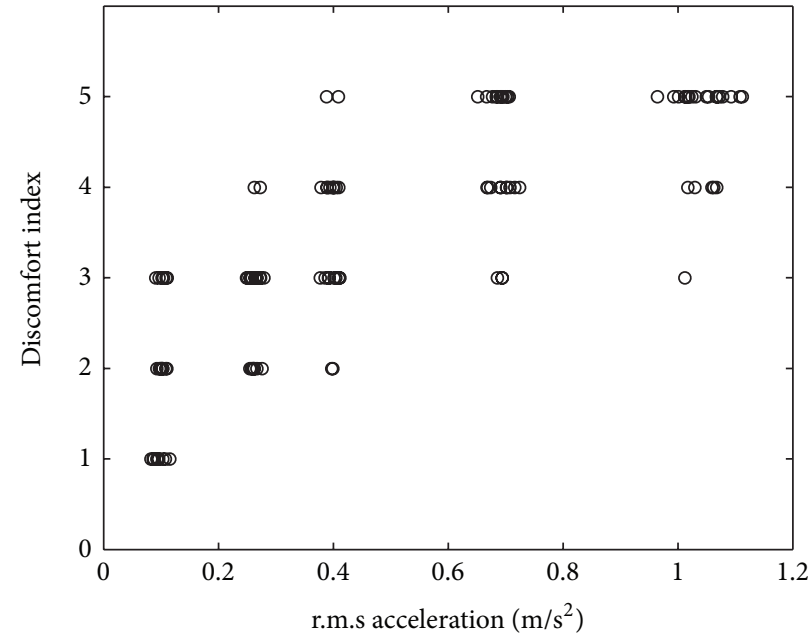

(b)

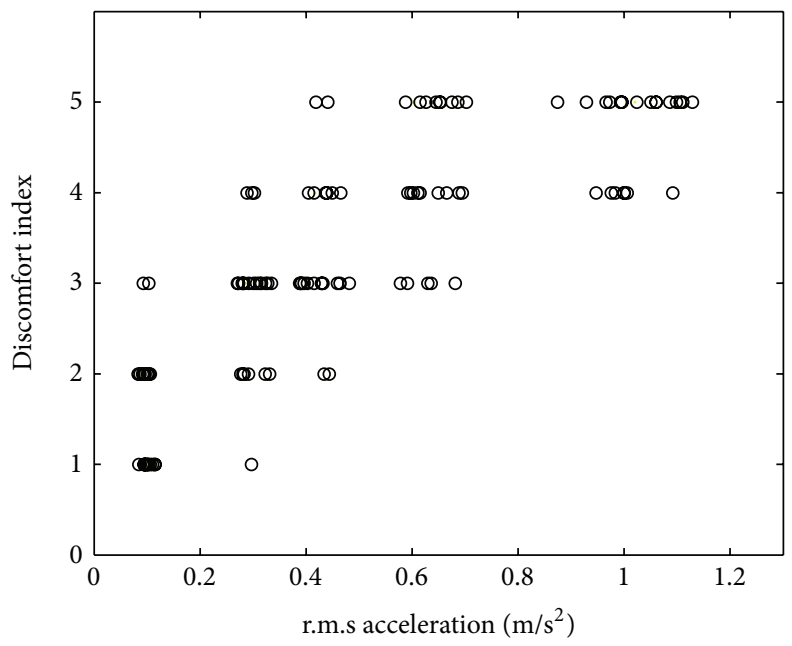

(d)

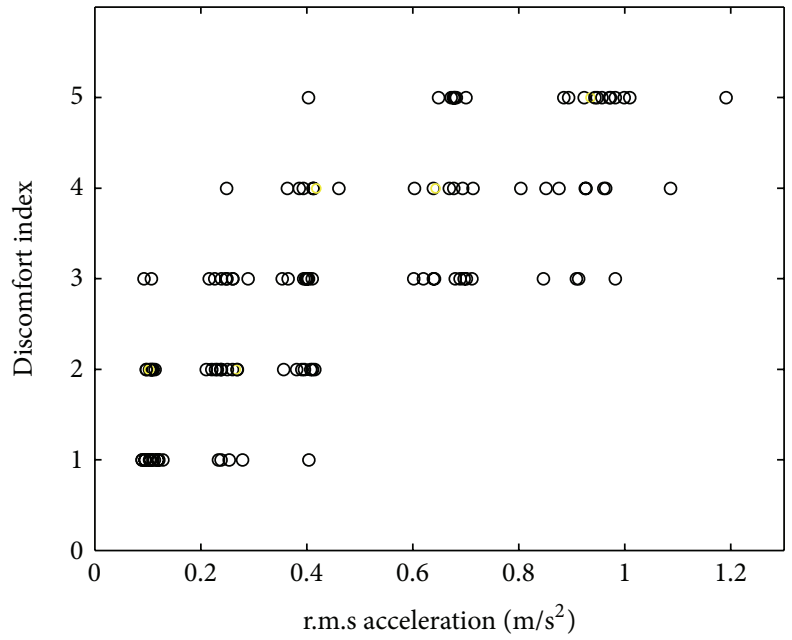

(e)

FIGURE 6: Perceived discomfort of seated subjects due to vibration on seat in heave mode input at (a) $3 \mathrm{~Hz}$, (b) $4 \mathrm{~Hz}$ (c) $6 \mathrm{~Hz}$, (d) $8 \mathrm{~Hz}$, and (e) $10 \mathrm{~Hz}$. 


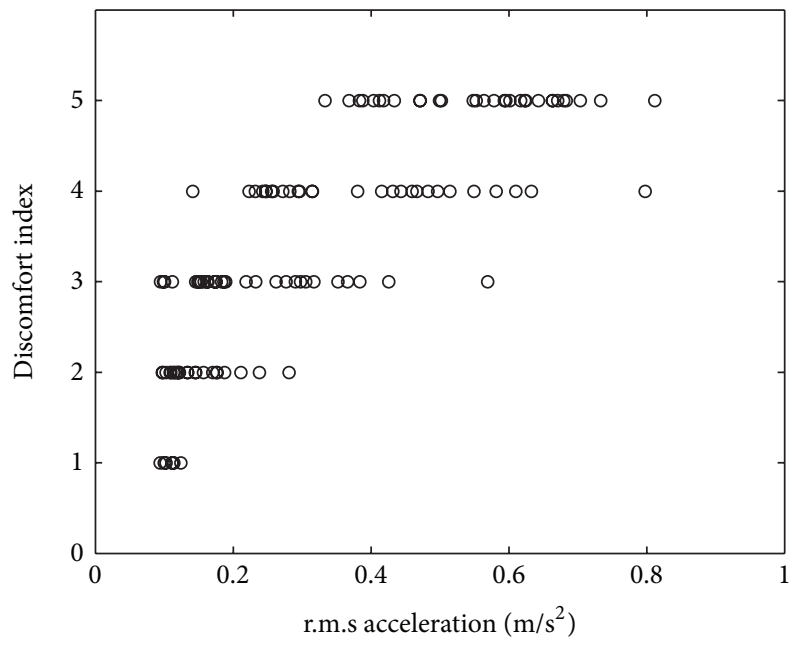

(a)

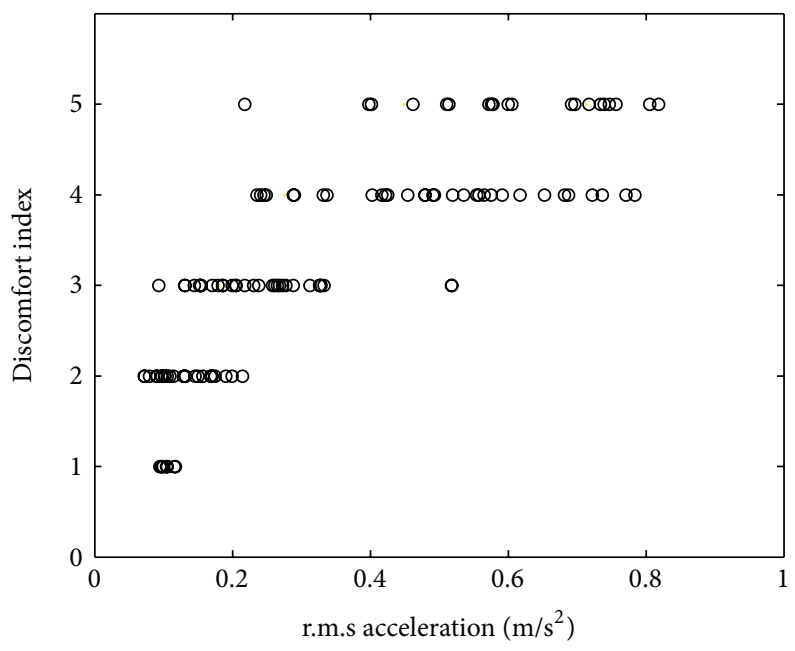

(c)

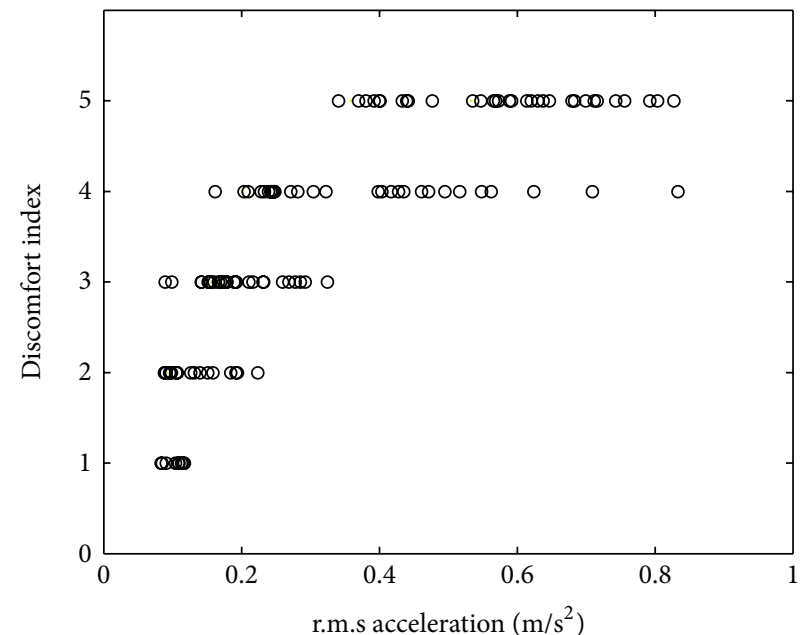

(b)

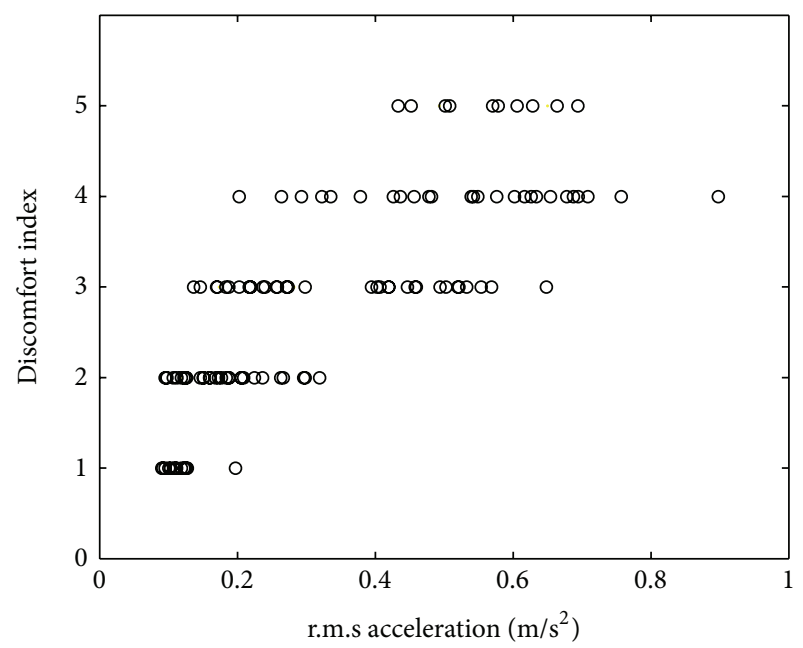

(d)

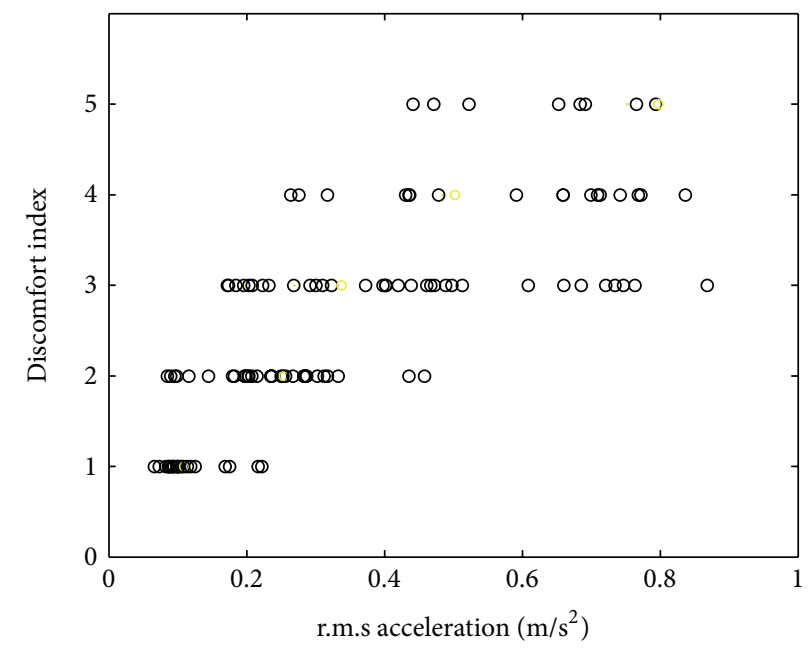

(e)

Figure 7: Perceived discomfort of a seated subject due to seat vibration in pitch mode input at (a) $3 \mathrm{~Hz}$, (b) $4 \mathrm{~Hz}$ (c) $6 \mathrm{~Hz}$, (d) $8 \mathrm{~Hz}$, and (e) $10 \mathrm{~Hz}$. 

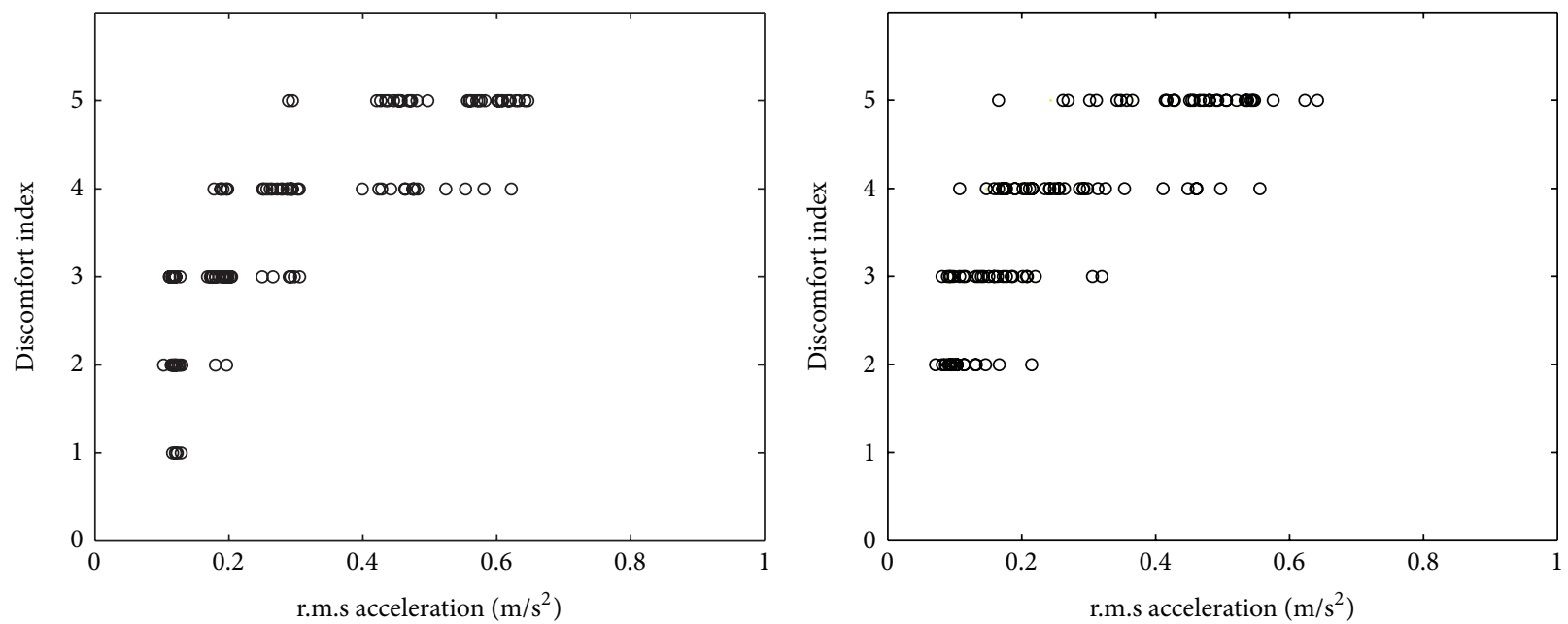

(a)

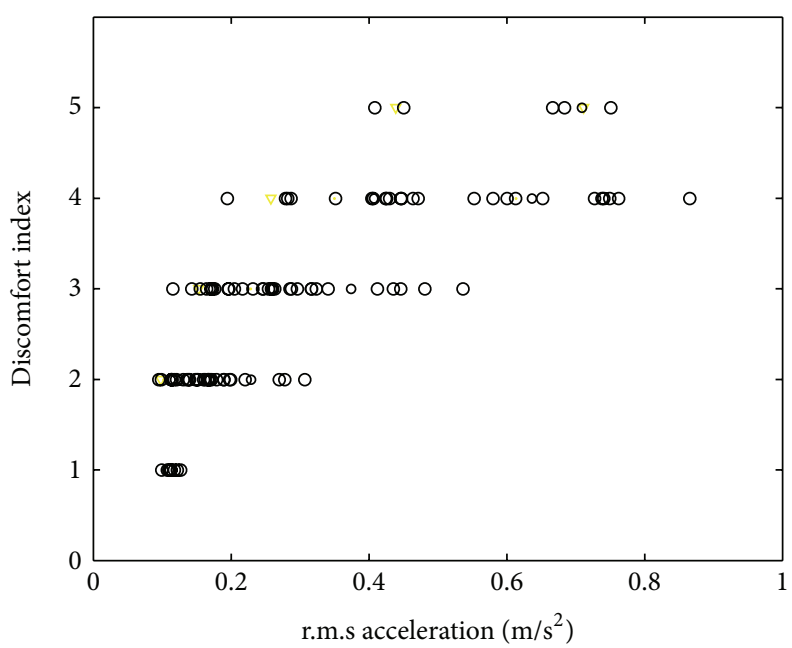

(c)

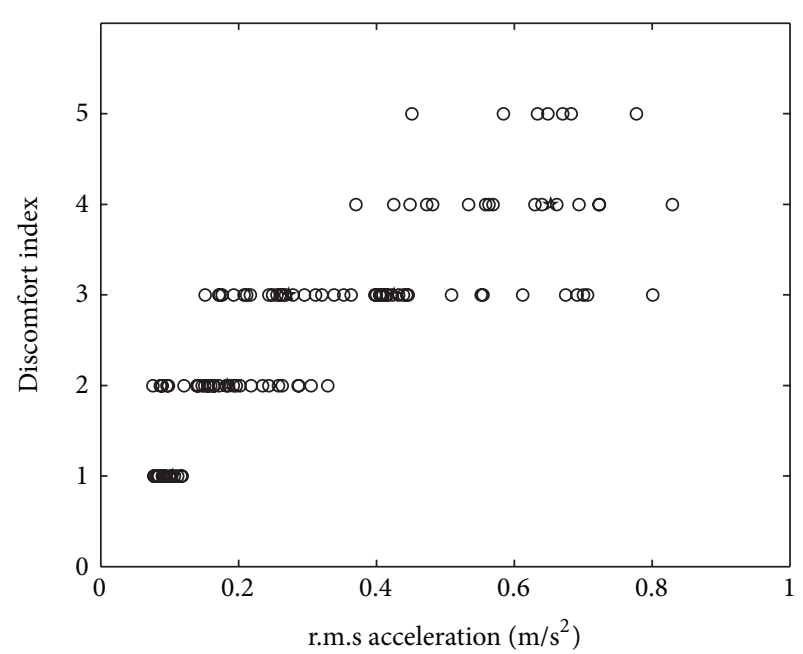

(d)

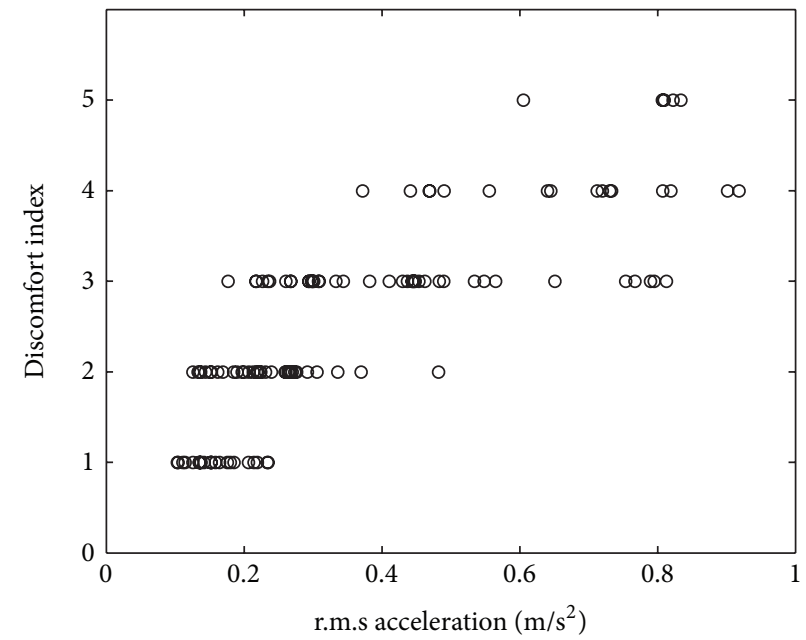

(e)

FIGURE 8: Perceived discomfort of a seated subject due to seat vibration in roll mode input at (a) $3 \mathrm{~Hz}$, (b) $4 \mathrm{~Hz}$ (c) $6 \mathrm{~Hz}$, (d) $8 \mathrm{~Hz}$, and (e) $10 \mathrm{~Hz}$. 
in perception is very complex and it is difficult to arrive at straightforward conclusion. The seat-occupant vibration response variability, however, can be discussed in terms of dominant resonance frequencies.

4.4. The Response Statistics. The perceived discomfort variability to some extent can be attributed to the variability in the seat accelerations. The mean and standard deviation can be calculated from the measured seat-occupant vibration responses at all input frequencies. For example, Figures 9(a) and 9(b) show standard deviation and mean values, respectively, for the heave mode of input. One of the significantly influencing factors is the participant's mass and its variation. The effect is frequency dependent; it is insignificant at lower frequencies below about $5 \mathrm{~Hz}$. This is in spite of vehicle natural frequencies occurring in the region below about $4 \mathrm{~Hz}$. It indicates that the occupant body mass is insignificant dynamically in comparison to the vehicle mass. In contrast, for excitation frequencies in the region of 6 to $13 \mathrm{~Hz}$, the standard deviation shows significant changes for, in particular, the lower amplitude of inputs. Here the resonance peaks, due to seat dynamics, observed in Figure 3 play an important role. The local modes of vibration are more influenced by the variation in occupant mass (4) and (5) and hence the acceleration response. The inputs, therefore, for frequencies between 6 and $13 \mathrm{~Hz}$ are difficult to replicate for every participant and hence the response of occupant-seat is expected to be influenced and in turn may influence perceived discomfort.

\section{Conclusions}

An occupant in a car on the four-post rig simulator was studied to analyse discomfort due to vibration. A new experimental method, using an occupant in a car on the 4-post rig simulator for the first time, was introduced to quantify discomfort in situ. The experiments allowed excitation in all possible directions allowing analysis of directional sensitivity and the frequency sensitivity of the human response to vibration input.

The human response was very sensitive to low frequency excitation which conforms with the earlier studies. The seated subjects were found to slightly change the seat response and in turn, to an extent, may have affected subjective rating. The general perception was that at small amplitudes the pitch mode felt discomfortable. As expected, perceived discomfort decreased with decreasing amplitude and increasing frequency. More importantly, the results deviate from published results for angular modes of inputs. The deviation can be attributed to the dynamics of the vehicle resulting from coupled motion.

The results here, to some extent, may be affected by the type of vehicle used. Overall, however, the four-post rig setup was successfully used in conducting human discomfort tests for a particular vehicle. Test setup can be used to study the effects of complex road inputs and eventually may reduce reliance on the road tests. The results of a category of vehicle, subsequently, can also be used to predict discomfort in new similar models.

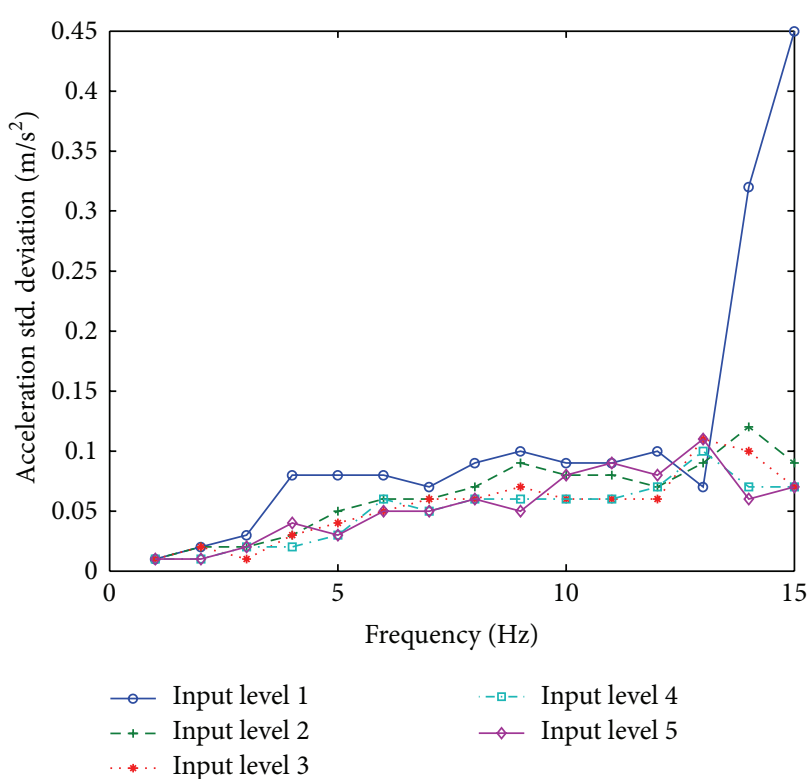

(a)

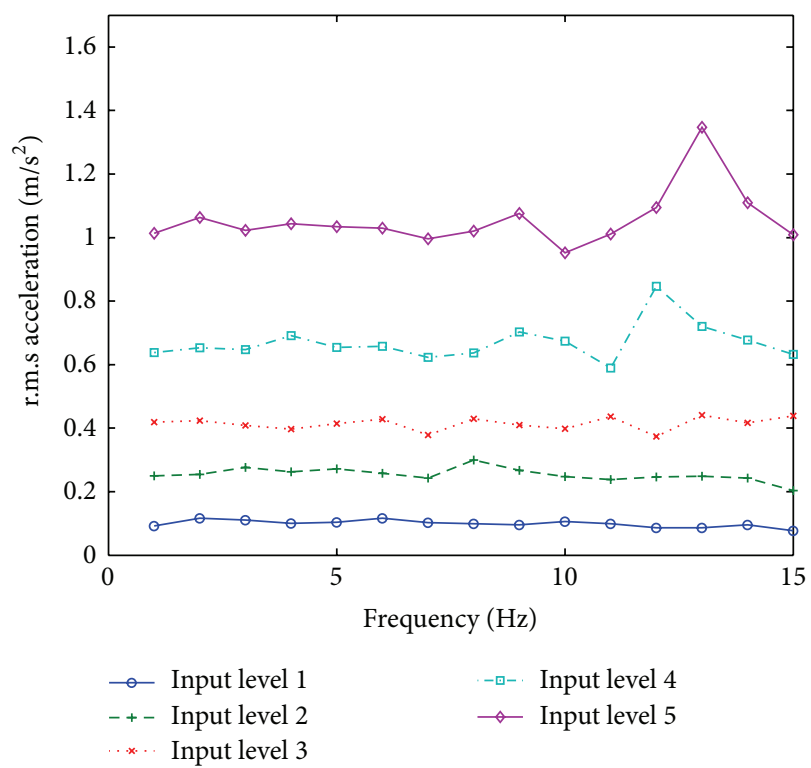

(b)

FIgURE 9: Seat acceleration statistics for heave mode of input. (a) Standard deviation of seat-occupant acceleration and (b) r.m.s seatoccupant acceleration.

The variability in intensity of perception for different modes of input is very complex. It is an interesting area to explore further with controlled experiments so as to correlate dynamics of participants and the perceived discomfort.

\section{Conflict of Interests}

The authors declare that there is no conflict of interests regarding the publication of this paper. 


\section{References}

[1] G. Kyung, M. A. Nussbaum, and K. Babski-Reeves, "Driver sitting comfort and discomfort (part I): use of subjective ratings in discriminating car seats and correspondence among ratings," International Journal of Industrial Ergonomics, vol. 38, no. 5-6, pp. 516-525, 2008.

[2] M. J. Griffin, Handbook of Human Vibration, Elsevier/Academic Press, London, UK, 1990.

[3] N. J. Mansfield, Human Response to Vibration, CRC Press, London, UK, 2005.

[4] A. J. Jones and D. J. Saunders, "Equal comfort contours for whole body vertical, pulsed sinusoidal vibration," Journal of Sound and Vibration, vol. 23, no. 1, pp. 1-14, 1972.

[5] B. Basri and M. J. Griffin, "Equivalent comfort contours for vertical seat vibration: effect of vibration magnitude and backrest inclination," Ergonomics, vol. 55, no. 8, pp. 909-922, 2012.

[6] G. S. Paddan, N. J. Mansfield, C. I. Arrowsmith, A. N. Rimell, S. K. King, and S. R. Holmes, "The influence of seat backrest angle on perceived discomfort during exposure to vertical wholebody vibration,” Ergonomics, vol. 55, no. 8, pp. 923-936, 2012.

[7] I. Kingma and J. H. van Dieën, "Car driving with and without a movable back support: effect on transmission of vibration through the trunk and on its consequences for muscle activation and spinal shrinkage," Ergonomics, vol. 52, no. 7, pp. 830-839, 2009.

[8] G. S. Paddan, S. R. Holmes, N. J. Mansfield et al., "The influence of seat backrest angle on human performance during wholebody vibration," Ergonomics, vol. 55, no. 1, pp. 114-128, 2012.

[9] ISO, "Mechanical vibration and shock: evaluation of human exposure to whole-body vibration part 1: general requirements, International Organization for Standardization," ISO 2631-1, 1997.

[10] J. L. van Niekerk, W. J. Pielemeier, and J. A. Greenberg, "The use of seat effective amplitude transmissibility (SEAT) values to predict dynamic seat comfort," Journal of Sound and Vibration, vol. 260, no. 5, pp. 867-888, 2003.

[11] M. S. Demić and J. K. Lukić, "Human body under two-directional random vibration," Journal of Low Frequency Noise Vibration and Active Control, vol. 27, no. 3, pp. 185-201, 2008.

[12] T. E. Fairley and M. J. Griffin, "The apparent mass of the seated human body: vertical vibration," Journal of Biomechanics, vol. 22, no. 2, pp. 81-94, 1989.

[13] T. M. Hacaambwa and J. Giacomin, "Subjective response to seated fore-and-aft direction whole-body vibration," International Journal of Industrial Ergonomics, vol. 37, no. 1, pp. 61-72, 2007.

[14] D. J. Oborne, "Vibration and passenger comfort: can data from subjects be used to predict passenger comfort?" Applied Ergonomics, vol. 9, no. 3, pp. 155-161, 1978.

[15] I. Kushiro, E. Yasuda, and S. Doi, "An analysis of pitch and bounce motion, requiring high performance of ride comfort," Vehicle System Dynamics, vol. 41, pp. 83-92, 2004.

[16] P. Jönsson and Ö. Johansson, "Prediction of vehicle discomfort from transient vibrations," Journal of Sound and Vibration, vol. 282, no. 3-5, pp. 1043-1064, 2005.

[17] T. Ibicek and A. Thite, "Quantification of human discomfort in a vehicle using a four-post rig excitation," Journal of Low Frequency Noise Vibration and Active Control, vol. 31, no. 1, pp. 29-42, 2012.

[18] “Dynasoft Multimatix MX user manual,” MTCA, 2008.
[19] I. G. Vanhees and I. M. Maes, "Vehicle suspension characterisation by using road simulation on a 4 poster test rig," in Proceedings of the 2002 International Conference on Noise and Vibration Engineering (ISMA '02), pp. 63-70, September 2002.

[20] L. C. Fothergill and M. J. Griffin, "The subjective magnitude of whole body vibration," Ergonomics, vol. 20, no. 5, pp. 521-533, 1977.

[21] S. Maeda, "Necessary research for standardization of subjective scaling of whole-body vibration," Industrial Health, vol. 43, no. 3, pp. 390-401, 2005.

[22] S. Maeda, N. J. Mansfield, and N. Shibata, "Evaluation of subjective responses to whole-body vibration exposure: effect of frequency content," International Journal of Industrial Ergonomics, vol. 38, no. 5-6, pp. 509-515, 2008. 

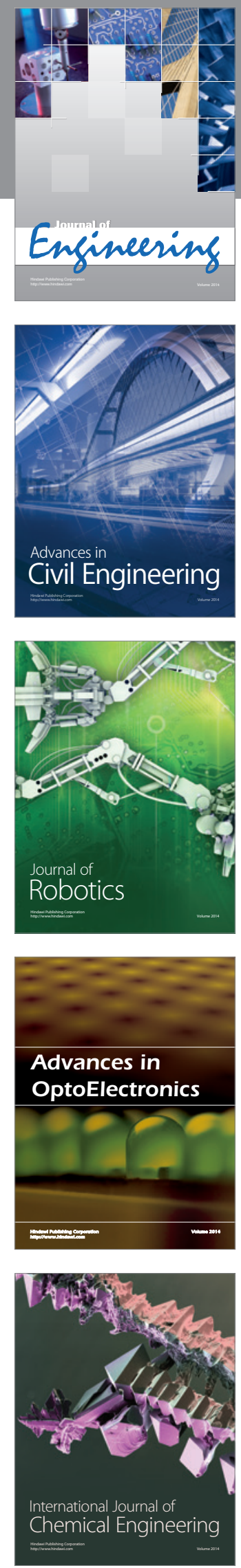

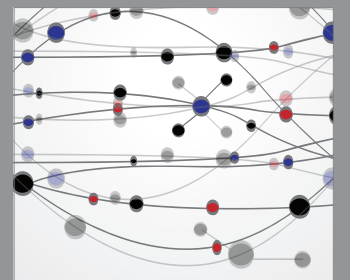

The Scientific World Journal
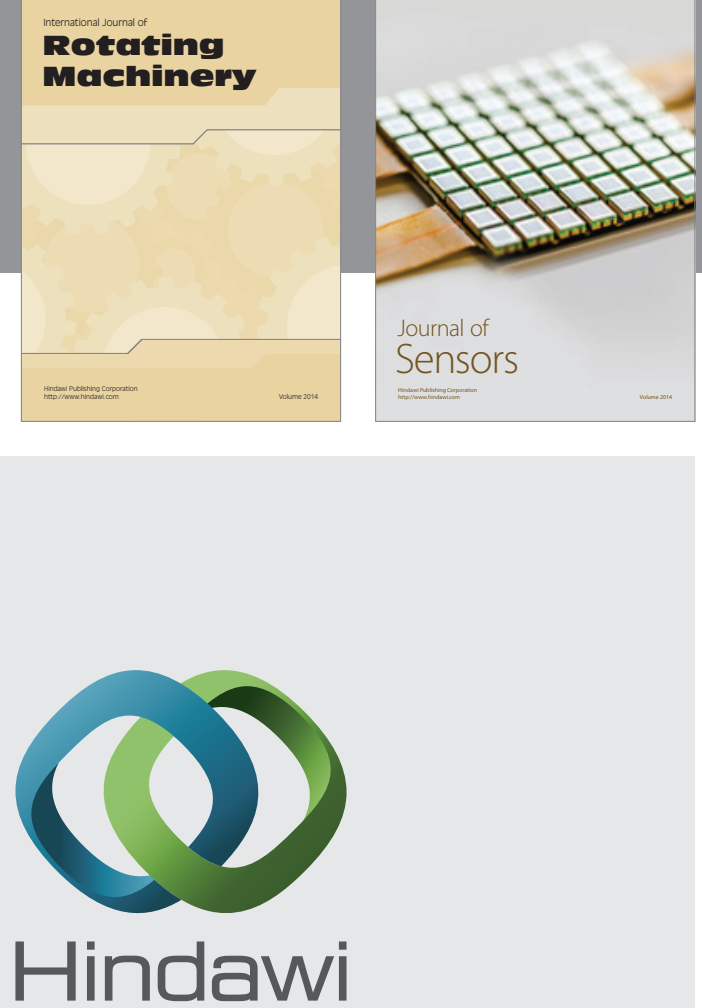

Submit your manuscripts at http://www.hindawi.com
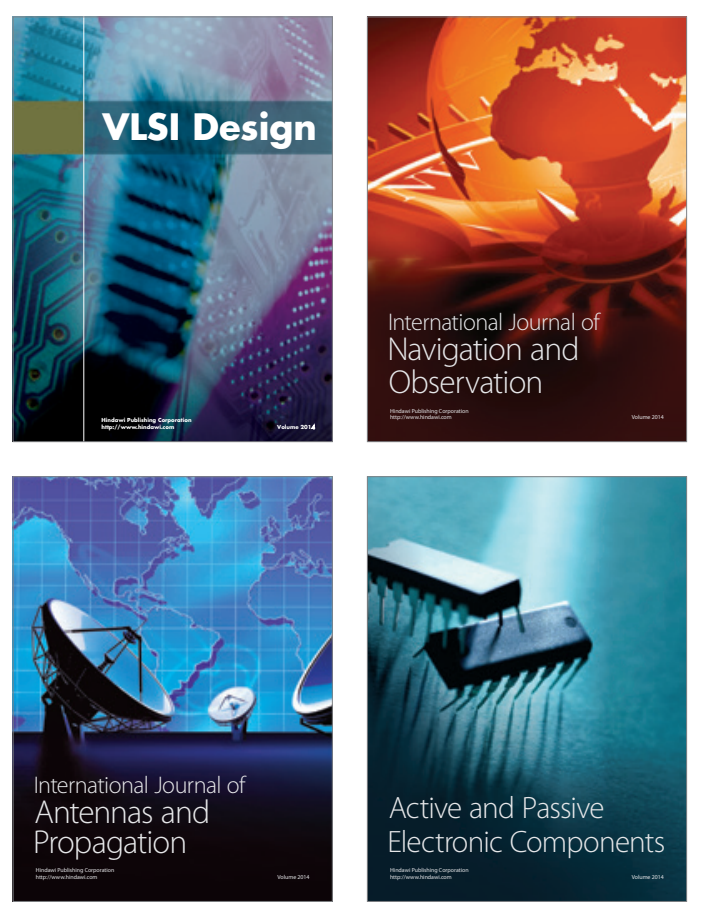
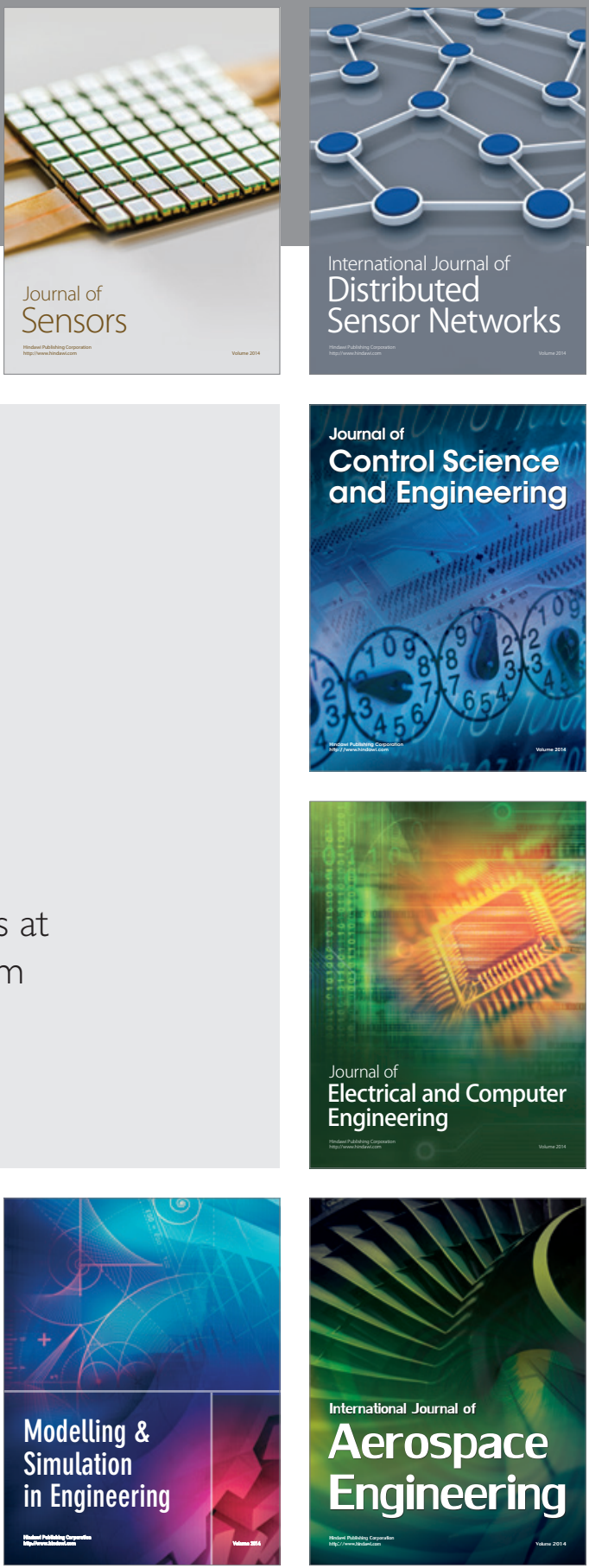

Journal of

Control Science

and Engineering
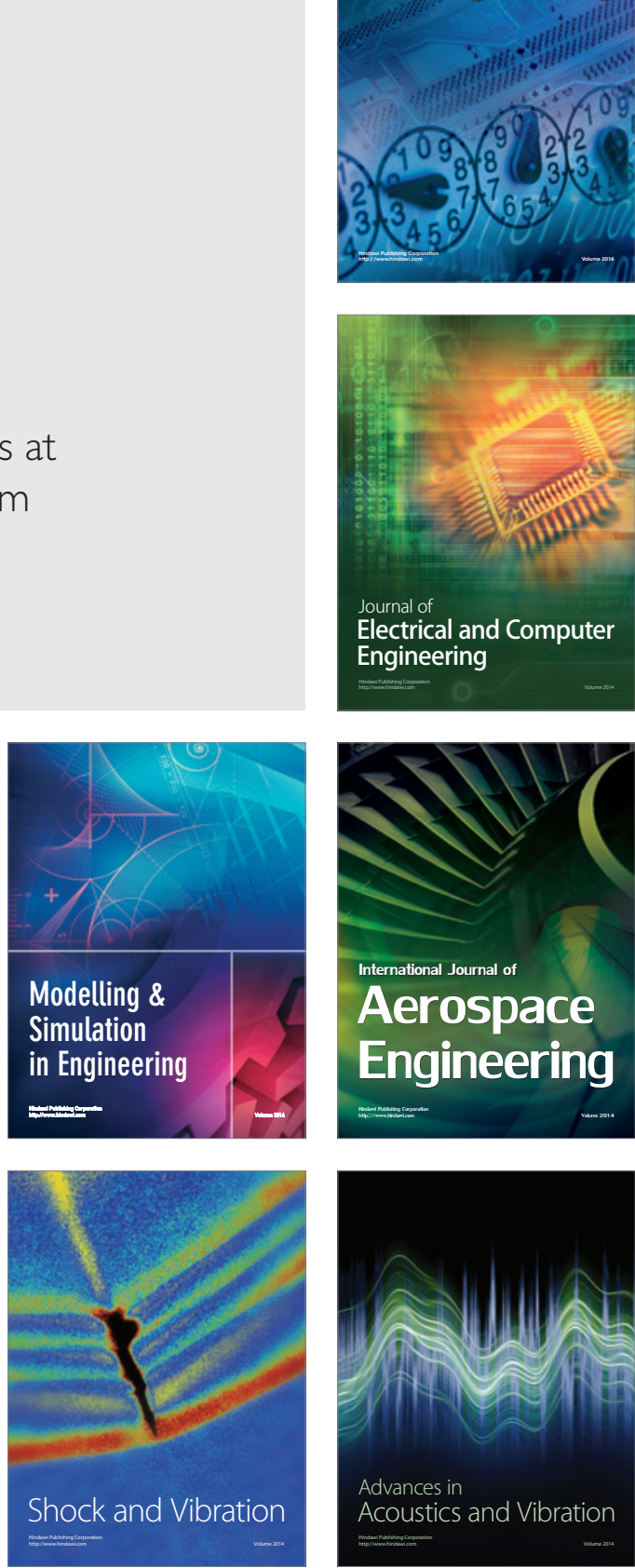